\title{
Impacts of LNG Export and Market Power on Australian Electricity Market Dynamics, 2016-2019
}

\author{
Dylan McConnell $^{1}$ (D) $\cdot$ Mike Sandiford $^{1}$
}

Accepted: 6 October 2020 / Published online: 9 November 2020

(C) Springer Nature Switzerland AG 2020

\begin{abstract}
Purpose of Review Supply-side shocks in concentrated energy markets provide opportunity for exercise of market power, especially in markets undergoing transition due to imperatives such as decarbonisation. In Australia, the recent linkage of international gas markets with the electricity market provides a useful example to review these dynamics.

Recent Findings Using the intersections between gas and electricity markets in Australia, we explore how (1) supply constraints associated with commencement of Liquefied Natural Gas (LNG) exports, and (2) market concentration due to closure of old coal plant, contributed to effect a doubling of wholesale electricity prices. The recent Australian experience highlights the disproportionate impact of gas generation on electricity prices due to its price-setting role. The price impact of the tightened gas market on electricity prices has been significantly exacerbated through the exercise of market power, especially via the practise of 'shadow pricing'. In the Australian case, the potential adverse intersectional impacts of LNG exports could have been substantially adverted with enforced domestic reservation of about $6 \%$ of LNG export volumes.
\end{abstract}

Summary Competition issues and gaming opportunities, which have accompanied the increased market concentration that accompanied the withdrawal of capacity, have exacerbated the price impacts of the supply-side shock stemming from the evolving gas market.

Keywords Decarbonisation · Energy transition $\cdot$ LNG exports $\cdot$ Market power

\section{Introduction}

The requirement to rapidly lower the emission intensity of our energy system is implicit to the success of global climate aspirations such as embedded in the Paris agreement. While there has been a large effort put towards understanding least-cost transition pathways in individual energy sectors, such as electricity (e.g. [1]), there has been rather less attention to how connections between various energy sectors play out in terms of market dynamics (but see [2]).

As a carbon-intensive economy with a strong historical reliance on fossil exports, Australia's experience with issues of decarbonisation have some unique attributes. The socalled 'climate wars' of the last 15 years have played out in

This article is part of the Topical Collection on Energy Markets

Dylan McConnell

dylan.mcconnell@unimelb.edu.au

1 School of Earth Science, University of Melbourne, Parkville, VIC, 3010, Australia the public and political domain. Arguably, the politicisation of Australia's decarbonisation challenge has played a primary role in the demise of its last four prime ministers.

The public discourse on decarbonisation in Australia has centred largely on the electricity sector, and has been sharpened by an extraordinary rise in wholesale electricity prices in 2016, both in relative and absolute terms. According to a European Commission analysis [3] (see Fig. 1) Australian prices (AEMO NEM) were lower than US (PJMWest/Ercott) prices, about half of European (Platts PEP) prices, and only 20\% of Japanese (JPEX) prices as recently as the last quarter of 2014. Just over two years later, in the first quarter of 2017, Australian prices had risen to, on average, more than JPEX, two times Platts PEP, and as much as four times PJMWest/Ercott. In absolute terms Australian prices doubled from less than \$40-50/MWh prior to 2016 , to $\$ 75-120 / \mathrm{MWh}$ in the period late 2016 through late 2019 (Fig. 2). This amounts to an annual increase in the notional value of the wholesale electricity market between 2015 and 2017 of about AUD\$14 billion.

Large increases in renewable energy supply, including domestic Solar PV, and the closure of a number of coal plants has lead to profound changes in power generation 
Fig. 1 International comparisons of wholesale prices adapted from Figure 33 in the European Commission's 2017 1st quarter Quarterly report on European Electricity Markets [3]. Average prices for the fourth quarter of 2014, third quarter 2015 , and the first quarter of 2017 are referenced as a percentage of Australian prices

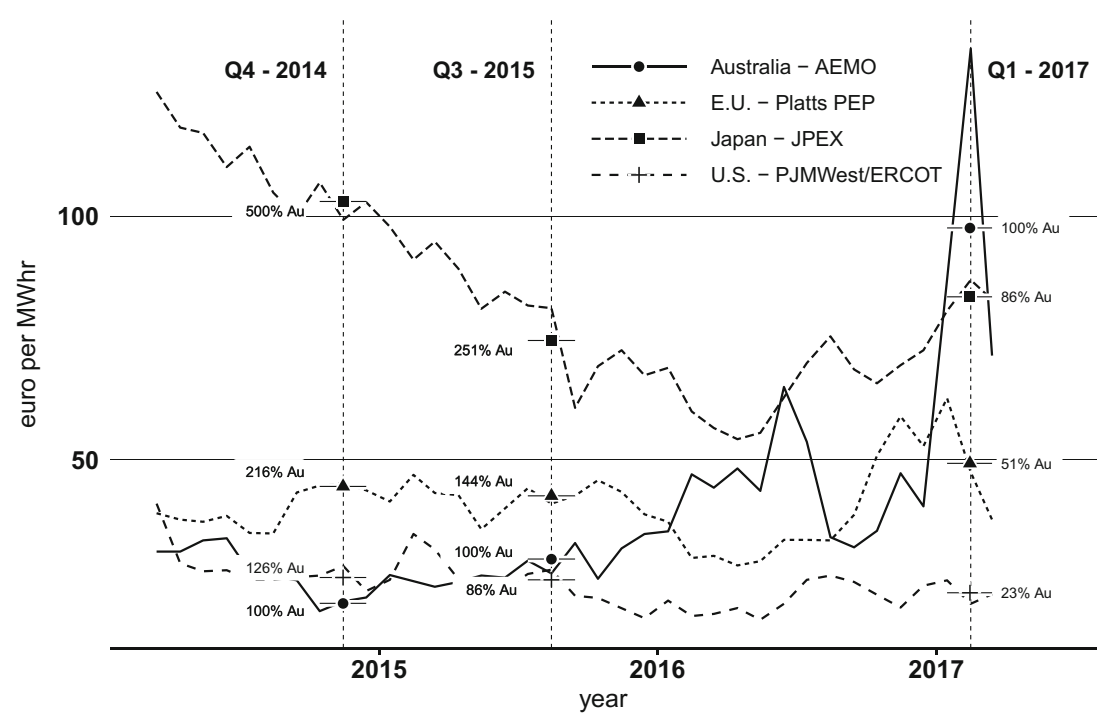

structure over this period. The contribution of wind and solar energy generation increased from $2 \%$ in the 2009 2010 financial year to almost $18 \%$ in the the 2019-2020 financial year. Over the same period, the contribution of coal generation has fallen from 81 to $67 \%$, and gas generation from 10.3 to $8.5 \%$. The period 2015-2017 also witnessed a threefold increase in gas production to supply Liquefied Natural Gas (LNG) exports at Curtis Island facility in Queensland $[4,5]$.

In this contribution we explore the linkages between the evolving Australian east coast gas export market and the electricity sector to illuminate how supply side shocks impact a liberalised wholesale electricity market under transition. While some related issues have been discussed by [2] our focus here is on the how the linkages impact competition in the electricity market. We begin with a brief discussion of

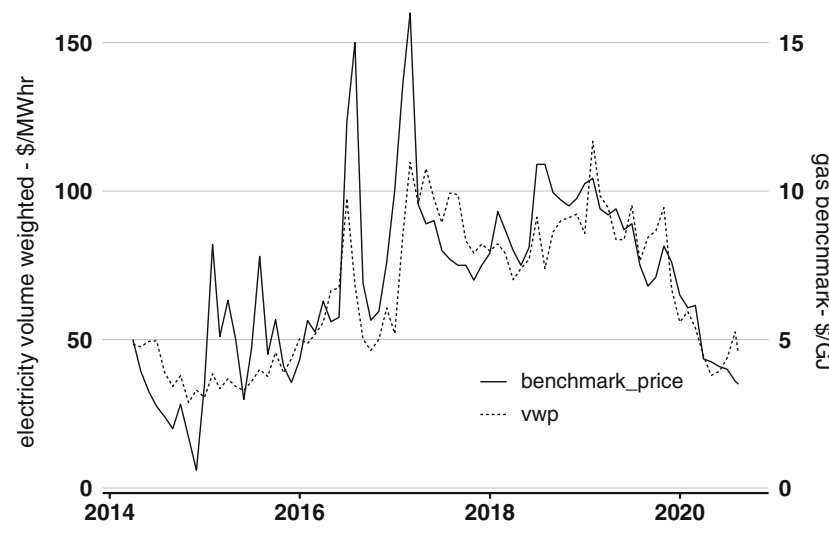

Fig. 2 Monthly averaged, volume-weighted Australian National Electricity Market (NEM) prices (dashed) and notional gas prices using the a composite of the Wallumbilla and South East Queensland (SEQ) hub price (solid), for the period 2014 to mid-2020. The electricity prices are calculated using settlement prices less than $\$ 300 / \mathrm{MWh}$, so as exclude extraneous market events such as plant and network outages, as occurred for example during the devastating bush-fires of late 2019 , early 2020 the the gas sector. We follow with an overview of the electricity market, focusing on changes in the level of market concentration and the role gas plays in price formation.

Our focus here is on the Eastern Australian energy markets which includes interconnections in both gas and electricity markets across the five regions of New South Wales (NSW), Queensland (QLD), South Australia (SA), Tasmania and Victoria (VIC) that comprise the the National Electricity Market (NEM). The NEM operator AEMO settles prices in each of the five participating and interconnected regions, each governed by identical market rules. The east coast gas market is more loosely structured, comprising a set of independent hubs supplied by three main production zones in Victoria, South Australia and Queensland [4].

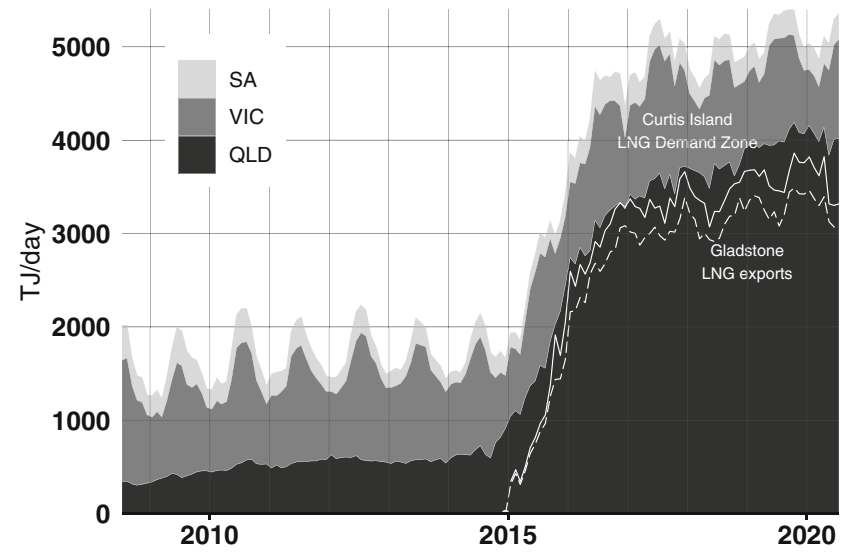

Fig. 3 Australian east coast gas market supply up until June 30, 2020, by the three main producing zones in Queensland (QLD), Victoria (VIC) and South Australia (SA). Also shown is the gas demand for the Curtis Island Demand zone (white line) that feeds the LNG supply trains, and the LNG exported volumes from the Gladstone Ports. Assuming an LNG energy content of $54.8 \mathrm{GJ} /$ tonne, the supply to Curtis Island is about $9 \%$ higher than the reported export volumes, reflecting in part the large component of gas used in liquefaction. Gas supply data from AEMO, LNG export data from the Gladstone Port Authority 
Fig. 4 a QLD gas supply (dashed) and Curtis Island (CI) demand (solid) from late 2016. Supply to Curtis Island commenced at the beginning of 2015 , but is only reported by AEMO from end of October, 2015. b QLD domestic supply balance, obtained by subtracting the CI-Demand from the QLD supply. In years 2010-2014, prior to opening the CI LNG export facility, the QLD gas supply averaged $460 \mathrm{TJ} /$ day. Despite QLD supply increasing almost ninefold after 2015, the residual supply available for dispatch into the traditional domestic market remained below $460 \mathrm{TJ} /$ day until mid-2019
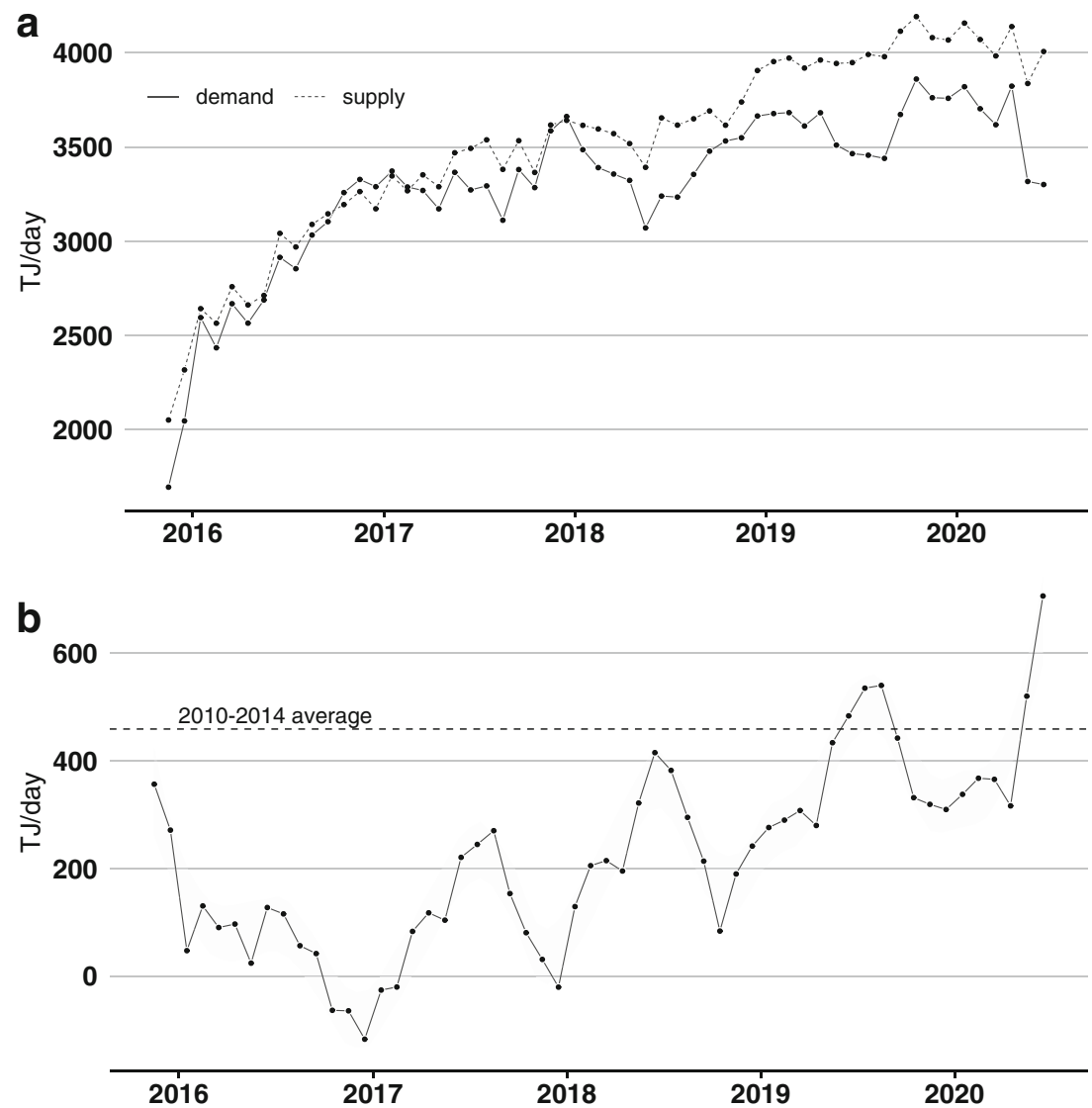

\section{Gas Demand and Prices}

In early 2015, exports of LNG commenced from Curtis Island at Gladstone in Queensland, for the first time exposing the east coast Australian gas market to international pricing [4]. The linkage to export markets has transformed Australia's east coast gas industry, almost tripling demand from an average of $1780 \mathrm{TJ} /$ day prior to 2015 to around $5000 \mathrm{TJ} /$ day in late 2017 (Fig. 3).

Almost all the new east coast gas demand has been met by production from newly developed coal seam gas (CSG) fields in Queensland, from which supply increased almost ninefold. Figures 4 and 5 show that as new fields were developed to supply LNG, the Queensland CSG supply available for the traditional domestic markets declined appreciably through 2016, before gradually recovering to pre-LNG levels by late 2019 (see also [4]). In late 2016 and again in late 2017, the Curtis Island demand for LNG (inclusive of exports and processing) exceeded total Queensland CSG production (Fig. 5a). The residual negative domestic balance from Queensland production was accommodated by imports from the more southern states, evidenced by flow reversals on the SWQ gas pipeline interconnector (Fig. 5b). The linkage to the international LNG and oil markets and the tightening of the domestic gas market had a dramatic impact on domestic gas prices (Fig. 2). Several drivers for this have been noted, including the relative high marginal cost of CSG production $[4,5]$. In the 'overs and unders' spot markets, where un-contracted gas is traded, prices rose from and average of about $\$ 4 / \mathrm{GJ}$ prior to 2016 to about \$9/GJ from 2016 through 2019 (Fig. 6).

\section{Impacts on the Electricity Sector}

The movements in domestic gas prices have directly effected the electricity sector in two related, but distinct ways. Firstly, they have increased the direct costs of generation via contractual arrangements. As existing gas supply agreements expired, new contracts were exposed to rising domestic gas price $[6, p .10]$. This is evidenced in the reported fuel costs for Torrens Island Power Station (TIPS) in SA. AEMO's 2013 National Transmission Network Development Plan (NTNDP) indicated TIPS fuel costs at approximately $\$ 4.40 / \mathrm{GJ}$. By 2015 the NTNDP was projecting TIPS 2016 prices in the range $\$ 7.35-\$ 8.59 / \mathrm{GJ}$ for 2016, an increase of more than $70 \%$ over three years (see Fig. 7). The 2020 iteration of the NTNDP reported TIPS fuel cost at $\$ 10.44 / \mathrm{GJ}$. 
Fig. 5 a Domestic supply balance, before and after opening the Curtis Island LNG facility in 2015, withe the latter obtained by subtracting the CIDemand from the QLD supply. b Gas flows on the SWQ pipeline that provides the only gas link from Queensland to the other states. Positive values reflect flows into Queensland (imports), negative flows are exports
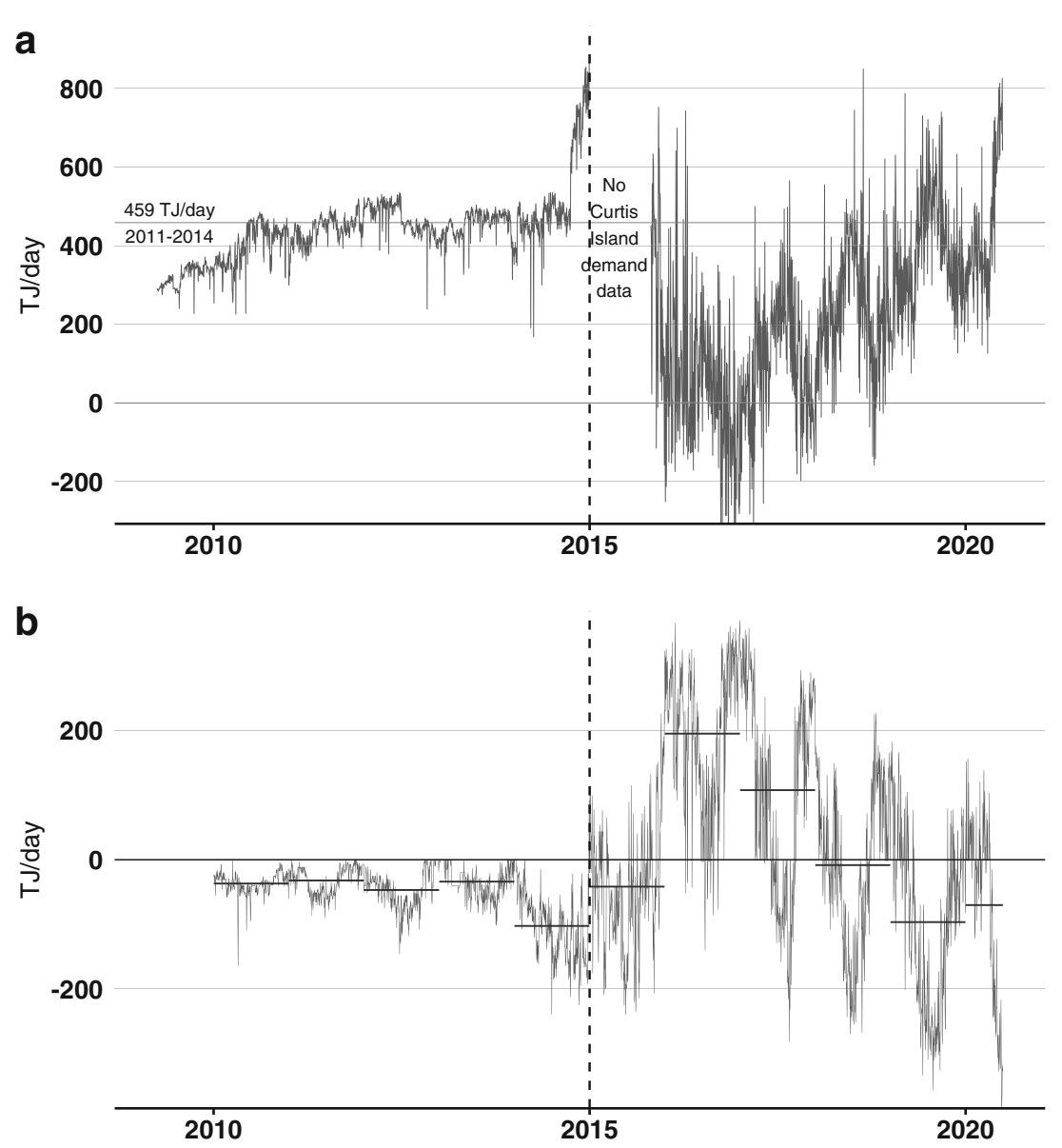

Secondly, gas generators normally procure some small un-contracted fraction of their supply at the spot price, further impacting the opportunity cost of gas generation. Depending on the contractual arrangements, gas from existing supply agreements may also be foregone, in a manner that is functionally equivalent to selling gas at the spot price. In either case, the opportunity cost of the marginal unit at a gas plant is influenced by the spot market, which in turn is linked to the international price.

Due to it's flexibility and position on the electricity dispatch merit curve, gas often plays a price setting role in wholesale electricity prices. Gas typically
Fig. 6 Gas spot price for the main Eastern seaboard demand hubs. Price for Sydney, Adelaide and Brisbane are from the Short Term Trading Market (STTM), while prices for Victoria are from the Declared Wholesale Gas Market (DWGM). Both markets show substantial increases in price following the development of the export market

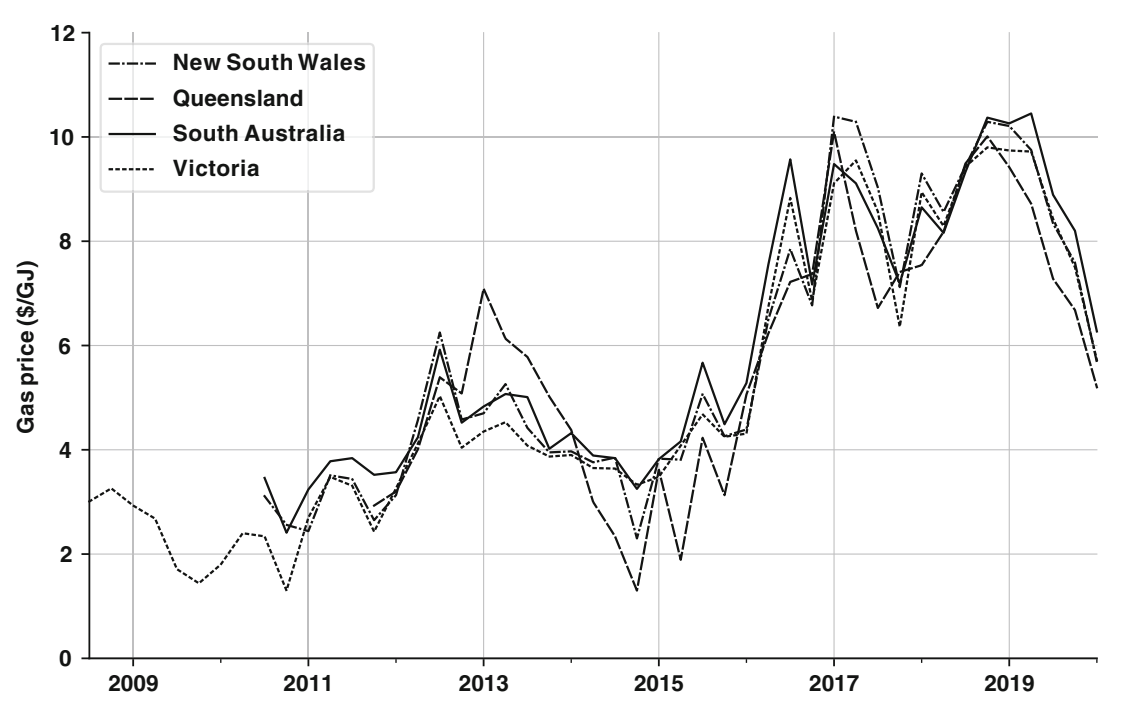


Fig. 7 Fuel cost projections for Torrens Island Power Station (TIPS), compared with previous years. Data from AEMO NTNDP 2015 and NTNDP 2013, see also 7

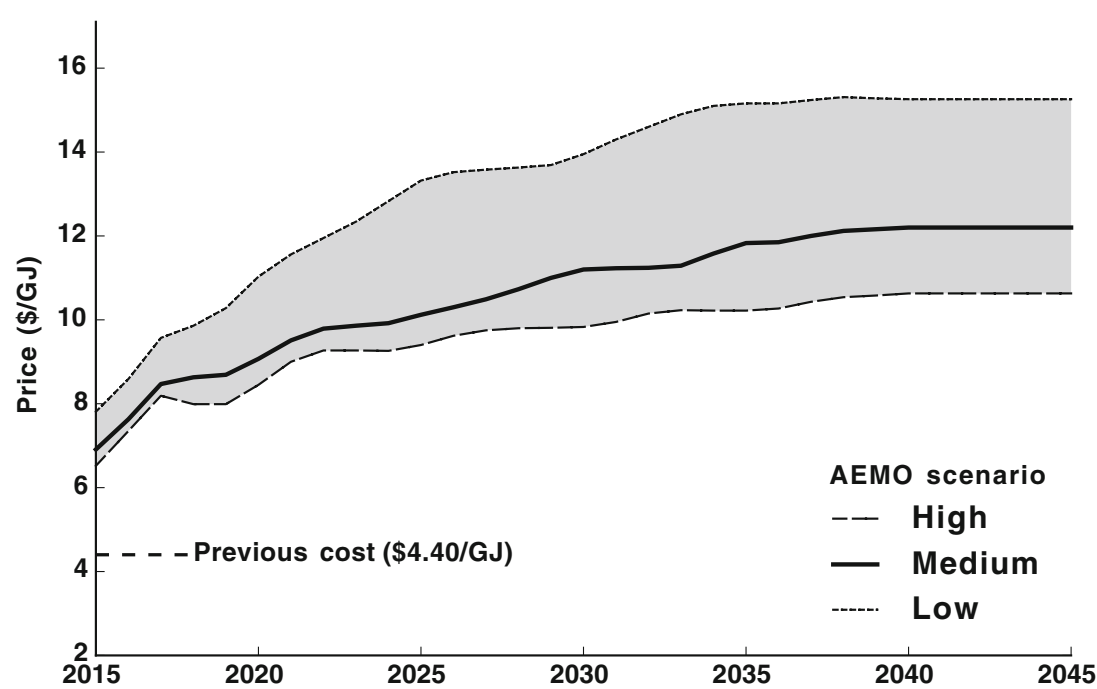

sets the price $10-20 \%$ of the time across the NEM, despite contributing less than $10 \%$ of total generation. This rate is much higher in jurisdictions such as SA where there is no (longer any) coal or other low marginal cost generation, other than renewable energy, as evidenced in the strongly correlated price movements on the gas and electricity markets (e.g. Fig. 8).

\section{Competition, Market Power and Shadow Pricing}

Gas prices have also manifestly impacted electricity prices in a third indirect way. Increasing market concentration has allowed some participants to exercise market power, over and above the marginal increase in fuel costs. In particular, the rising gas price has incentivised the practise of 'shadow pricing' amongst coal generators.

\section{Competition in Systems Under Transition}

Transitional arrangements in the NEM have seen the closure of several large power stations, alongside the expansion of renewable energy generation. In addition to the tightening of the demand-supply balance, which inevitably created significant upward pressure on price and increased volatility, these closures have increased market concentration, as evidenced by a number of measures as outlined below.
Fig. 8 Relationship between South Australian electricity prices (daily volume weighted prices) and daily gas spot prices (ex post STTM prices) for the period January 2015 through July 2016. The correlation coefficient for the 7 day moving average is 0.86 a Daily

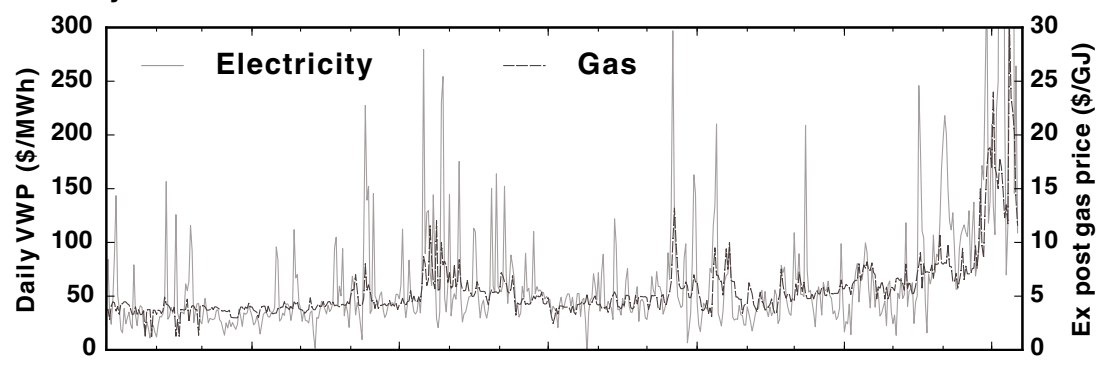

b 7-day moving average

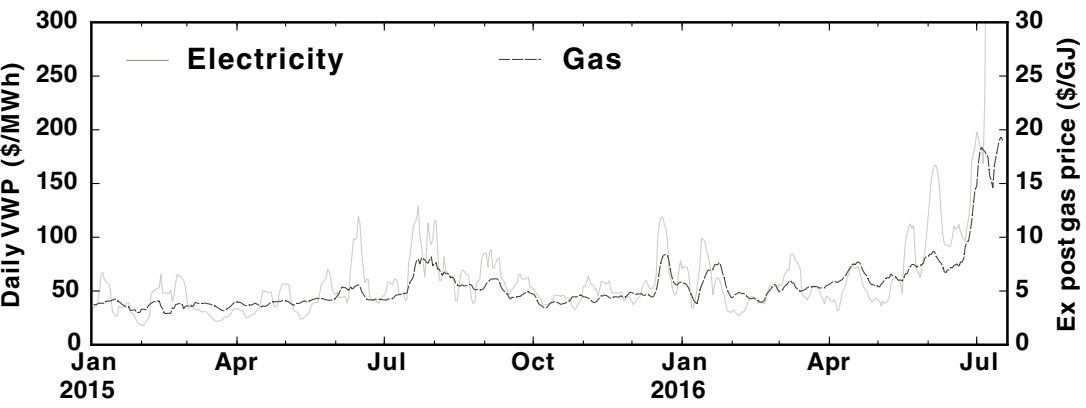


Competition has long been identified as a particular issue in the SA regional market (e.g. [7-9]). One of the reports [7] documented cases in 2008-2011, and another looked at how reduced market prices from wind generation in South Australia was mitigated due to the exercise of market power [8]. A report prepared for the South Australian Council of Social Services [9] in 2013 also examined 18 different high priced events in detail, concluding that generators deliberately sought to maximise profit in times tight supply.

The AEMC's 2013 review on market power reported that SA was 'prone to inhibiting efficient investment and promoting the likelihood of substantial market power' [10]. The Commission accepted that there are some circumstances in which substantial market power could be exercised in the NEM, and specifically identified the potential for substantial market power to be exercised in South Australia.

Since the 2013 AEMC review, significnat conctration has occurrred. In SA, the two coal generation plants have closed (the 240 MW Platford B and 520 MW Northern Power Stations in May 2016). Northern represented about 39\% in percentage terms of median regional demand, which we refer to as regional basis size. Their closure has enhanced the market power of AGL, as the major holder of SA gas assets. In VIC, the 1600 MW Hazelwood Power Station (regional basis size 32\%) closed in March 2017. In NSW, two of the largest black coal power stations (Liddell and Bayswater) with a combined regional basis sizes of $58 \%$ were consolidated under AGL's control in September 2014. All have had impacts on the level of competition, which we discuss below, with reference to several measures of market concentration.

\section{Measures of Concentration}

\section{Herfindahl-Hirschman Index}

The Herfindahl-Hirschman index (HHI) is a commonly used static measure of market concentration, reported annually by the Australian Energy Regulator (AER) in the 'State of the Energy' market report (e.g. [11, p. 60]). The HHI is calculated by summing the squares of the percentage market shares for all firms participating in a market. An HHI value of 10,000 is equivalent to a $100 \%$ share, and represents complete monopoly. An HHI value of 2000 is used by the ACCC to flag competition concerns [12, p. 37], while the U.S. Department of Justice considers markets to be unconcentrated at below 1500, moderately concentrated at 1500-2500 and highly concentrated at 2500 [13, pp. $18,19]$. Perhaps more apposite to energy markets are the UK's Office of Gas and Electricity Markets (OFGEM) guidelines. The OFGEM regards an HHI exceeding 1000 as concentrated and above 2000 as very concentrated [14, p. 37]. With a current HHI value of 1243 [14, p. 64], the
OFGEM considers the UK wholesale electricity market somewhat concentrated.

In the three years FY2012 through FY2015, AER's HHI estimates for SA, NSW and VIC are in the range 17002000, with QLD in the range 2300-2450. The 2020 report from the AER shows further deterioration in the level of concentration, with HHI values in all four regions now in the 2000-2500 range [15].

Based on the trading rights indicated in the 2015 AER report [11, pp. 40, 41], we estimate the HHI for SA at the end of FY2016 was about 2900-3000 with all registered plants available. In our calculation of the current HHI we follow AER's methodology of de-rating the wind and interconnector capacity, based on their contribution to peak demand. The value is substantially higher than AER has reported in the previous years reflecting the concentration of market share that followed the closure of Northern Power Station.

\section{Pivotal Supply Index}

Indices like the HHI based on static measures such as installed capacity do not fully account for system dynamics such as the exercise of transient market power. Several alternative measures have been proposed to capture such transients, including the 'Pivotal Supplier Index' (PSI) discussed here. The PSI calculates the frequency that some quantity from a given supplier is required to serve market demand. Under such conditions, the required participant becomes a monopoly supplier of the portion of demand that cannot otherwise be served [16, p. 7].

The PSI is calculated by subtracting the total amount of generation made available by other generators and interconnector import limits from the total demand. If a generator is required to meet to the remaining demand, it is said to be 'pivotal'. A pivotal participant is necessarily essential to serving market demand, even considering all demand and imports available from the rest of the market. When operating in pivotal mode, a market participant is in a position to extract monopoly rents, as distinct from scarcity rents. 'Pivotal' profits are those that accrue from the monopolistic restriction of supply to raise price without fear of entry by rivals.

Figure 9 illustrates the pivotal supplier index for the four mainland NEM regions. This is based on the dynamic available generation and available import capacity, and the largest firm capacity controlled by a single participant. In SA, VIC, and NSW, the pivotal supplier is AGL, while in QLD it is the Stanwell Corporation. The PSI index for SA is typically higher than for QLD and VIC, and mostly higher than NSW. Increases in NSW's PSI in early 2016 can be attributed to scheduled plant outages of coal plants, combined with the consolidation in AGL's holdings in 2014. 
Fig. 9 Monthly Pivotal Supply Index for the mainland NEM regions. The dark line shows the pivotal supply index based on the largest generator in the region, while the dashed line shows the index based on the amount of firm generation capacity controlled by a single firm. The closure of a $1600 \mathrm{MW}$ Victorian power station in early 2017 and it's impact on competition is clearly visible with this metric
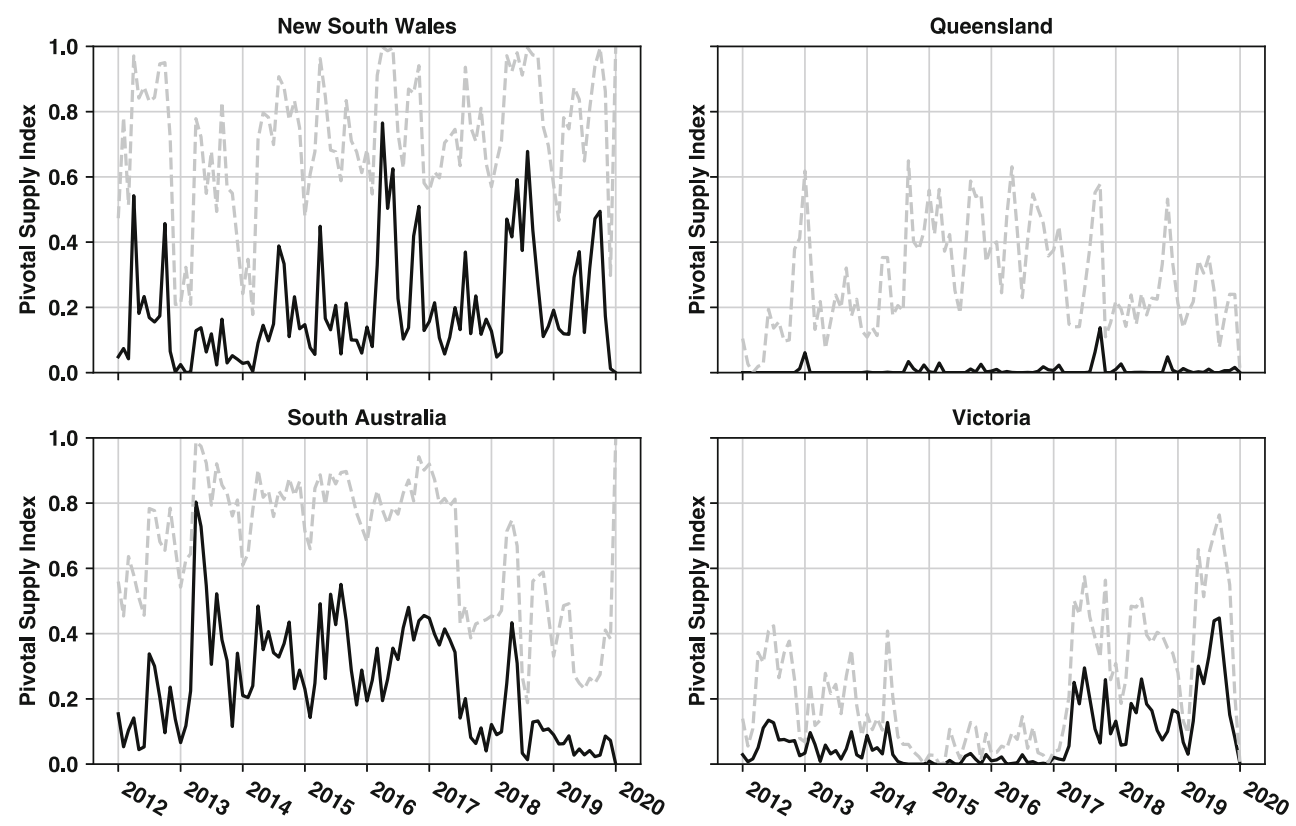

— Pivotal generator

- Pivotal firm

\section{Price-Cost Margins and 'Shadow Pricing'}

The fundamental measure of the degree of market power exercised is the price-cost margin [16]. In this Section we look at the price-cost margin for coal generation, and explore the practice of 'shadow pricing'.

Price-cost margins are difficult to assess reliably, because costs are usually proprietary information. As a proxy measure, we look at the so-called spark spread and dark spread. The spark spread represents the theoretical margin that a gas generator receives for a unit of power after deducting fuel costs, while the dark spread is the equivalent measure for a coal plant. All other costs including operation and maintenance, as well as financing and capital costs, must be recovered from the spread margin.

Panel a in Fig. 10 illustrates the spark spread for gas generation in SA using standard assumptions for heat rates. The theoretical margins for QLD, NSW and SA are
Fig. 10 a Spark spread for a typical Combined Cycle Gas Turbine with an assumed thermal efficiency of $50 \%$. b Comparison of margins between regions. Note that the price-cost margin increased considerably in SA, shortly after the retirement of Norther Power Station in May 2016-the last coal power station

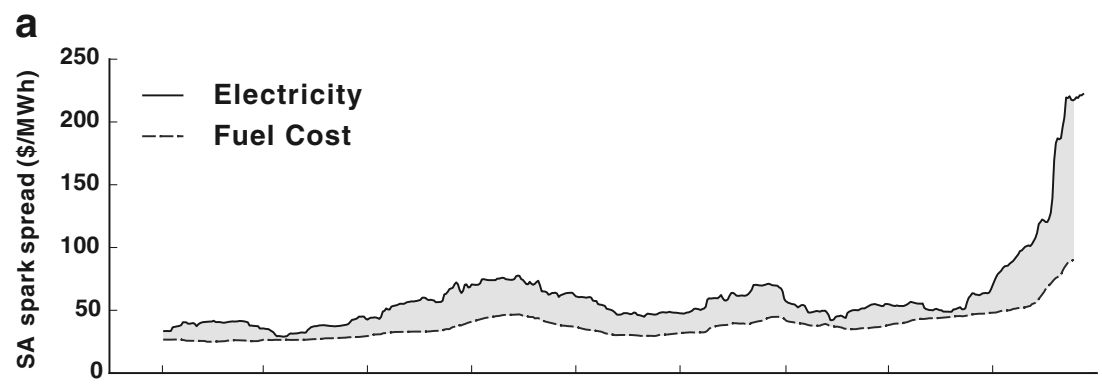

b

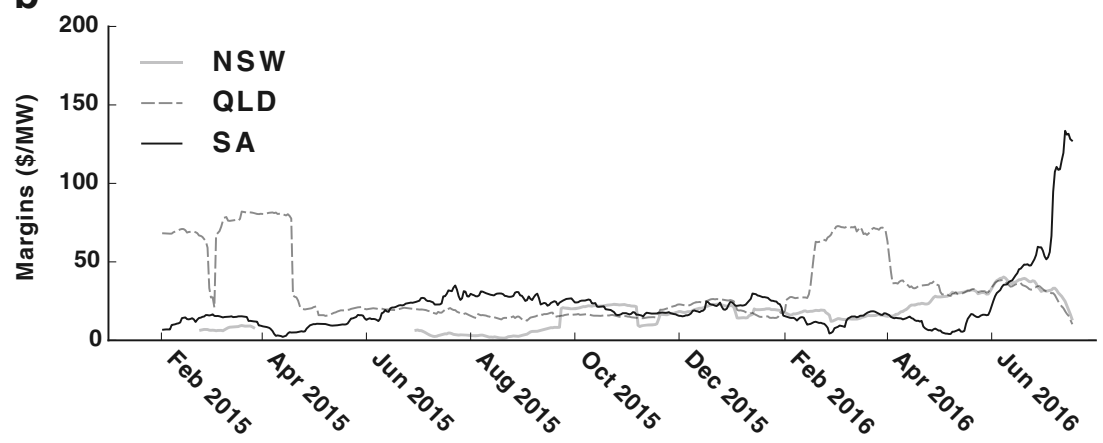




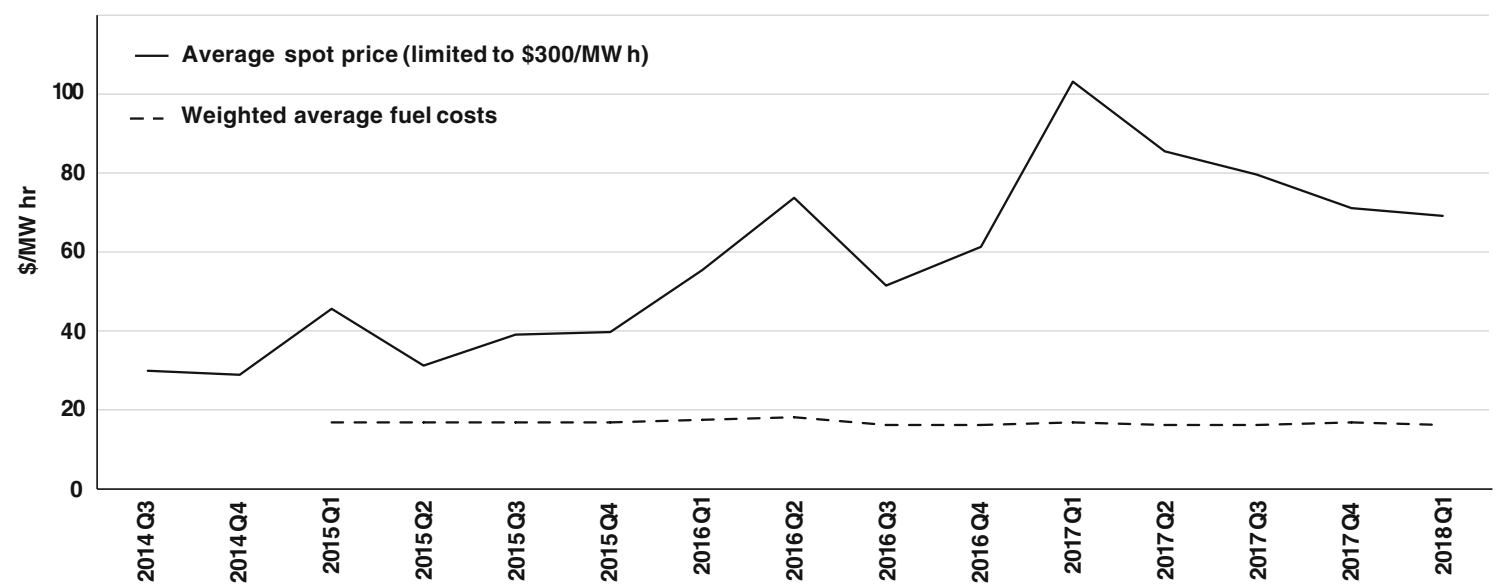

Fig. 11 Weighted average quarterly QLD black coal generators' fuel costs and Queensland wholesale prices, Q3 2014 to Q1 2018. Unlike the previous figure for gas, the weighted fuel cost was published by an inquiry by the competition regulator, and is based on real data

compared in panel b, since February 2015. Prior to June 2016, the spark spread was relatively constant and broadly consistent across the three regions, with the exception of the late summer and early autumn period when QLD spark spread was elevated by a factor of about four. Prior to June 2016, the SA spark spread averaged $\$ 17.34$, comparable to other unrelated jurisdictions such as the $\mathrm{UK}^{1}$.

Similarly, Fig. 11 illustrates the dark spread for QLD coal generation. In the period analysed, black coal produced more than $80 \%$ of QLD supply, with gas accounting for approximately $13 \%$. In this case, the weighted fuel cost was published by an inquiry by the competition regulator, based on real data acquired via the regulator's information gathering powers [17]. As with gas, there has been a noticeable divergence between costs and prices, suggestive of exercise of market power.

Taken in isolation, the observation that black coal margins are linked to domestic gas prices, in a region dominated by coal is surprising in terms of an efficient market. However, considered through the lens of market concentration, it is an expected behaviour of monopolistic participants. Specifically, the absence of competitive pressure allows coal generators to adopt a bidding strategy that 'shadows' the gas price. A pervasive culture of shadow pricing has been revealed by the competition regulator [17] who quoted from internal documents obtained from generator, noting that one:

... bid our remaining coal generation at the staggered prices that ensure full dispatch at the highest possible price before gas generators start.

and another that a main driver for higher spot prices was:

\footnotetext{
${ }^{1}$ See UK's spark spread at https://www.ofgem.gov.uk/chart/ spark-and-dark-spreads-gb
}

acquired via the regulators information gathering powers. The difference between the two lines represents the dark spread, and has widened considerably in recent years, indicating an increase in price-cost margin

... [b]lack coal bidding at higher prices-shadowing gas with volume that was bid at $\$ 40-\$ 50 / \mathrm{MWh}$ in 2016 now at \$70-\$100/MWh.

While not a direct measure of price-cost margins, there are additional lines of evidence that the price increases in the NEM go beyond an efficient equilibrium consistent with exercise of market power. For example, Fig. 12 shows that whereas prior to 2016 there was no systemic correlation between NEM prices and gas prices, from 2016 a strong correlation (\$9.6/MWh per $\$ 1 / \mathrm{GJ})$ was established. A correlation of this order would only be expected if gas generation with a thermal efficiency of $40 \%$ setting the price all the time, and yet in the period 2016+ gas generators set the price only around $10-20 \%$ of the time [18]. In the absence of a gas price shock, the market power may have been less of an issue. Alternatively, a more competitive market would have mitigated against the practice of shadow pricing. That the combination of the two have provided a 'perfect storm' for extremely elevated electricity prices is further evidenced by the relaxation in prices since late 2019, and especially in the second quarter of 2020 (Fig. 12), due to loosening of gas supply constraints in part as COVID-19 subdues global and domestic demand.

\section{Summary}

Given the deep linkages between energy sectors it is unsurprising that shocks in one sector propagate via other related markets and thence onto the broader economy. Attributing cause and effect in the chain of events can be problematic, especially when multiple potential causes intersect. Several previous studies have explored some aspects of the linkages between Australian gas and 


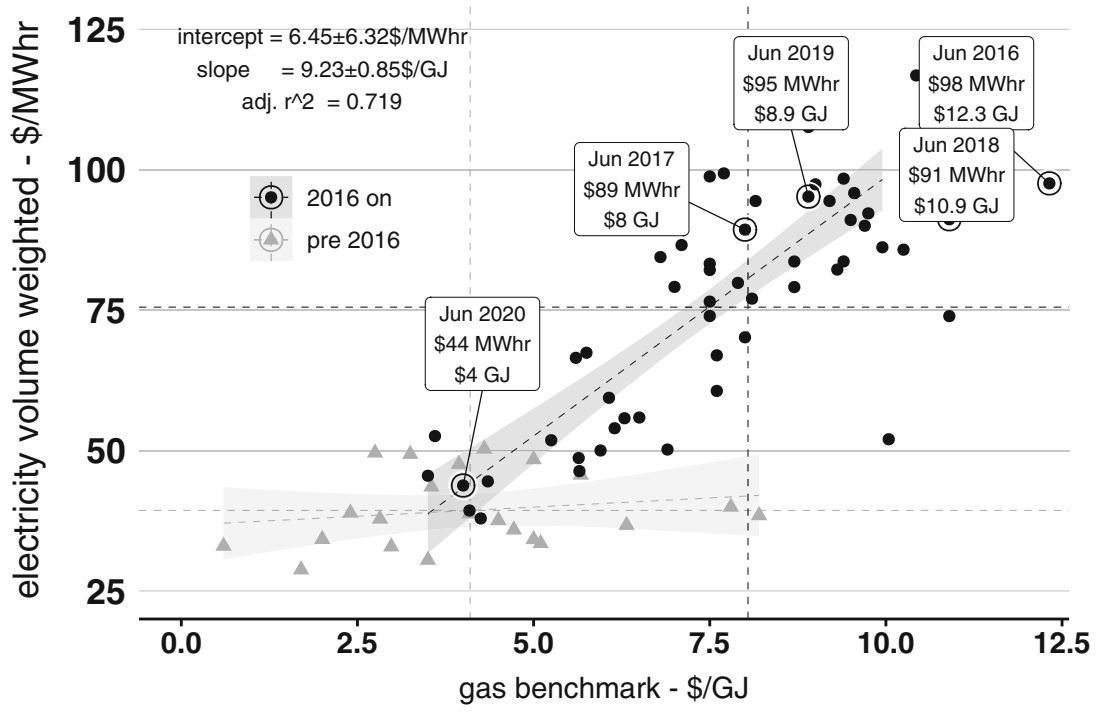

Fig. 12 Monthly averaged NEM-wide volume weighted electricity prices vs benchmark gas prices (Wallumbilla hub price in Queensland). Data prior to 2016 is shown in red, while data from 2016 onward is shown in blue, and the June data points are annotated. Prior to 2016, the gas price had little bearing on wholesale electricity market prices.

electricity markets $[4,5]$. Here we have extended this further by exploring how the impact of such intersections can be exacerbated in markets under transition forced by external drivers such as decarbonisation.

Several significant changes have impacted the functioning of Australian energy markets in recent years. These include the mandating of Renewable Energy Targets, the closure of large coal power plants, declines in domestic oil production and the opening up of the east Australian market to LNG export. We have focused on the gas markets and how from 2015 a ninefold increase in production from newly developed coal seam gas (CSG) fields in Queensland lead to tightening of the domestic gas market in the period 2016-2019 accompanied by 2-3-fold increase in both gas and electricity markets (see also [4, 5]). Ideological political narratives have clouded public perceptions of the causes of energy price rises.

The potential for the opening up of LNG exports to adversely impact the domestic energy markets was long recognised, as evident in a quote from a 2013 federal government report [19] demonstrates the concern:

The current development of LNG in Eastern Australia and the expected tripling of gas demand are creating conditions that are in stark contrast to those in the previously isolated domestic gas market. The timely development of gas resources will be important to ensure that supply is available for domestic gas users and to meet LNG export commitments. Such is the scale of the LNG projects that even small deviations from the CSG reserve development schedule could
From 2016 onward, a correlation has developed, with electricity prices increasing approximately $\$ 9.6 / \mathrm{MW}$ per $\$ 1 / \mathrm{GJ}$ increase in gas price. This would be consistent with a gas generator with a thermal efficiency of $40 \%$ setting the price all the time, and yet in this period gas generators set the price $10-20 \%$ of the time, depending on the region

result in significant volumes of gas being sourced from traditional domestic market supplies.

In the Australian context the mooted 'deviations ... in development schedule' were made very real by the absence of any domestic reservation requirement for CSG production. In the period 2016-2019 the production from the Queensland CSG fields was insufficient to meet combined QLD LNG export and local demand, with the consequence that significant volumes of gas were sourced from other gas producing regions connected to the Eastern Australian gas network, with consequent impact on gas prices through the east cost network. What was not anticipated was how changes in the electricity market generation structure impacted the way the settlement of electricity prices responded to the tightening of the domestic gas supply.

As part of any transition in the electricity sector, abrupt shifts in market power will necessarily accompany closure of large power stations. The exit of large coal fired power stations, alongside the expansion of renewable energy generation has bought with it several opportunities and challenges, some of which are detailed herein. The tightening of the demand-supply balance inevitably created significant upward pressure on price and increased volatility [2] as is consistent with the notion of the capacity cycle. Competition issues and gaming opportunities have accompanied the increased market concentration that accompanied the withdrawal of capacity, exacerbating the price impacts of the supply side shock stemming from the evolving gas market. 


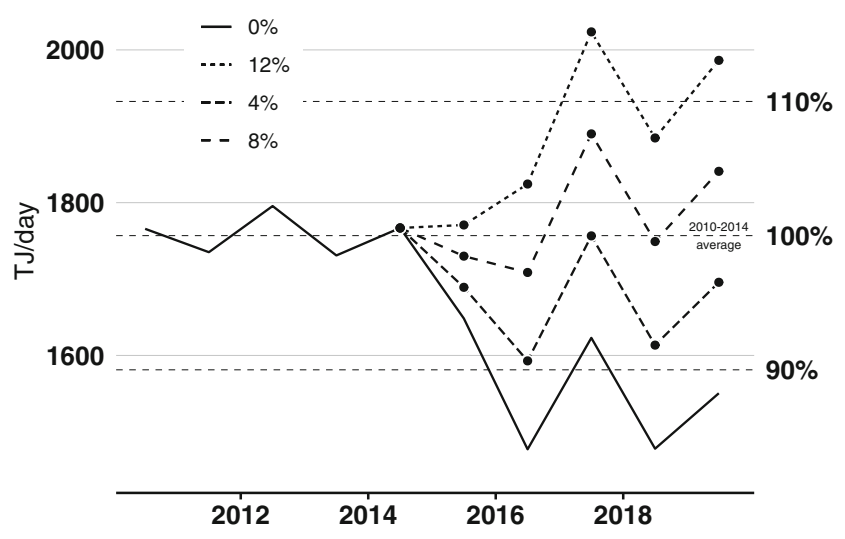

Fig. 13 Annual average residual domestic gas supply (solid black), obtained by subtracting Curtis Island demand from the east coast supply. Colours show the predicted domestic gas supply for 4, 8 and $12 \%$ domestic reservation of the exported LNG volume, including liquefaction demand

As a final comment, it is worth considering how the intersectional issues addressed here may have been circumvented. A measure that would have substantially ameliorated the issues would have been domestic reservation of a component of the CSG gas developed for LNG export. Such was the magnitude of the new CSG developments, the temporary reservation for domestic use of just $6 \%$ of the LNG export volume would have substantially averted the tightening of the domestic gas market over the period 2016-2019 (Fig. 13). A number of previous studies have addressed the question of domestic reservation $[4,5,20]$, concluding that when considered in terms of the gas market alone domestic reservation would result in suboptimal distortions. However, as we have shown in the absence of domestic reservation, the additional intersectional issues have contributed to extreme distortions in the electricity market, highlighting the need for more a more comprehensive national interest policy for gas allocation [20]. The absence of mandated reservation has effectively allowed gas exporters to defer some of the risk of meeting export production schedules onto domestic electricity consumers.

\section{References}

1. Elliston B, MacGill I, Diesendorf M. Least cost 100\% renewable electricity scenarios in the Australian National Electricity Market. Energy Policy. 2013;59:270-82.

2. Simshauser P. Garbage can theory and Australia's National Electricity Market: decarbonisation in a hostile policy environment. Energy Policy. 2018;120:697-13. http://www.sciencedirect.com/ science/article/pii/S0301421518303860.
3. European Commission MOE. Quarterly report on European Electricity Markets. 2017. https://ec.europa.eu/energy/sites/ener/ files/electricity_marketqreports_2017.zip.

4. Grafton R, Shi X, Cronshaw I. Making cents of the Eastern Australian Gas Market. Economic Papers: A journal of applied economics and policy. 2017;37:42-54. https://doi.org/10.1111/ 1759-3441.12194.

5. Simshauser P, Nelson T. Australia's coal seam gas boom and the LNG entry result. Australian Journal of Agricultural and Resource Economics. 2015;59(4):602-23.

6. Australian Energy Market Operator. 2016 Gas Statement of Opportunities. 2016. http://www.aemo.com.au/Gas/Planning/ Gas-Statement-of-Opportunities.

7. Mountain B. Electricity market power in South Australia. 2012. http://www.competitiontribunal.gov.au/__data/assets/pdf_file/0015/ 25044/energy-users-association-of-australia-accc-report.pdf.

8. Mountain B. Market power and generation from renewables: the case of wind in the south Australian electricity market. Economics of energy \& environmental policy. 2013;2(1):55-72. https://www.vu.edu.au/sites/default/files/cses/pdfs/market-powergeneration-from-renewables-aer2.pdf.

9. Carnegie Mellon University. High SA Electricity Prices: A Market Power Play? Prepared for South Australian Council for Social Services. 2016. https://www.sacoss.org.au/high-sa-electricity-pricesmarket-power-play.

10. Australian Energy Market Commission. Potential Generator Market Power in the NEM. 2013. http://aemc.gov.au/Rule-Changes/ Potential-Generator-Market-Power-in-the-NEM.

11. Australian Energy Regulator. State of the energy market 2015. 2015. https://www.aer.gov.au/publications/state-of-the-energy-mar ket-reports/state-of-the-energy-market-2015.

12. Australian Competition and Consumer Commission. Merger guidelines. 2008. https://www.accc.gov.au/system/files/Mergerguidelines.pdf.

13. U.S. Department of Justice and Federal Trade Commission. Horizontal Merger Guidelines. 2010. https://www.justice.gov/atr/ horizontal-merger-guidelines-08192010\#5c.

14. Office of Gas and Electricity Markets. Wholesale Energy Markets in 2015. 2015. https://www.ofgem.gov.uk/publicationsand-updates/wholesale-energy-markets-2015.

15. Australian Energy Regulator. State of the energy market 2020. 2020. https://www.aer.gov.au/publications/state-of-the-energy-mar ket-reports/-of-the-energy-market-2020.

16. Bushnell J, Knittel CR, Wolak F. Estimating the opportunities for market power in a deregulated wisconsin electricity market, the journal of industrial economics, 47. 1999. http://citeseerx. ist.psu.edu/viewdoc/download?doi=10.1.1.31.9666\&rep=rep1\& type $=$ pdf.

17. Australian Competition and Consumer Commission. Retail electricity pricing inquiry - final report. 2018.

18. AEMO. Quarterly energy dynamics, australian energy market operator. https://aemo.com.au/energy-systems/major-publications/quarterly-energy-dynamics-qed.

19. Department of Industry and Bureau of Resources and Energy Economics. Eastern australian domestic gas market study. 2013. https://www.scribd.com/document/420911216/ Eastern-Australian-Domestic-Gas-Market-Study.

20. Taylor ME. Is gas security in the 'national interest'?: An australian eastern gas market perspective. Routledge Handbook of Energy Law, Routledge; 2020. p. 445-67.

Publisher's Note Springer Nature remains neutral with regard to jurisdictional claims in published maps and institutional affiliations. 